\title{
Produtividade de grãos e frações nitrogenadas do milho submetido a manejo de adubos orgânicos na região semiárida
}

\section{Grain productivity and nitrogen fractions of maize under organic fertilization in semiarid region Brazil}

\author{
Tácio Oliveira da Silva ${ }^{1 *}$; Rômulo Simões Cezar Menezes ${ }^{2}$; Romildo Nicolau \\ Alves $^{3}$; Dário Costa Primo ${ }^{4}$; Geraldo Bruno Marques dos Santos Silva ${ }^{5}$
}

\section{Resumo}

\begin{abstract}
Visou-se avaliar, neste trabalho, a aplicação de adubos orgânicos sobre as frações nitrogenadas e a sua relação com a produtividade do milho na região semiárida. $\mathrm{O}$ milho foi cultivado em um Neossolo Flúvico em parcelas distribuídas em blocos ao acaso com quatro repetições e oito tratamentos arranjados em esquema fatorial $(2 \times 3)+2$, incluindo dois métodos de aplicação dos adubos (incorporado ou em superfície) e quatro tipos de adubação $\left(15\right.$ t.ha $^{-1}$ de biomassa de gliricidia, 15 t.ha ${ }^{-1}$ de biomassa de marmeleiro, 15 t.ha $^{-1}$ de esterco) e parcelas controle sem adubação. Os adubos orgânicos e os modos de aplicação ao solo influenciaram de forma diferente a produtividade de grãos e a nutrição do milho. Os três tipos de adubos, quando aplicados em superfície, incrementaram produtividade de grãos e os teores de $\mathrm{N}$ nos grãos. $\mathrm{O}$ teor maior de $\mathrm{N}$ foliar foi maior na gliricidia em superfície. $\mathrm{O}$ teor de $\mathrm{N}$ solúvel foliar incrementou com o controle e marmeleiro incorporados e gliricidia aplicada em superfície. O esterco em superfície incrementou o teor de $\mathrm{P}$ foliar, enquanto o K com o marmeleiro incorporado ao solo. As frações nitrogenadas no tecido foliar não acompanharam a tendência da produtividade de grãos, ou seja, os tratamentos que proporcionaram as maiores produtividades de grãos apresentaram as menores frações nitrogenadas.
\end{abstract}

Palavras-chave: Adubação verde, esterco bovino, nitrogênio, Zea mays L., Gliricídia sepium

\begin{abstract}
The objective of this study was to evaluate the effects of different organic fertilization treatments on maize grain productivity and nitrogen fractions in semi-arid NE Brazil. The experimental plots were established in a Entissol in randomized blocks in a factorial design $(2 \times 3)+2$ that included two methods of fertilizer application (surface applied or incorporated) and three types of organic fertilization (15 t.ha $\mathrm{a}^{-1}$ of animal manure, 15 t.ha- $\mathrm{a}^{-1}$ Gliricidia sepium prunings, $15 \mathrm{t}^{\mathrm{th}} \mathrm{a}^{-1}$ of Croton sonderianus prunings) and control plots without fertilization). The method of application and the three types of organic fertilizer had different effects on maize grain productivity and nutrition. For example, all types of organic fertilizers, when surface applied, significantly increased maize grain productivity and $\mathrm{N}$ concentration. Maize leaf
\end{abstract}

\footnotetext{
1 Prof. Adjunto, Universidade Federal de Sergipe, UFS, Dept ${ }^{\circ}$ de Engenharia Agronômica, Av. Marechal Rondon, s/n, Rosa Elze, 49100-000, São Cristóvão, SE. E-mail: tacio.oliveira@pq.cnpq.br

2 Prof. Adjunto, Universidade Federal de Pernambuco, UFPE, Dept ${ }^{\circ}$ de Energia Nuclear, Av. Prof. Luiz Freire, 1000, Cidade Universitária, 50740-540, Recife, PE. E-mail: rmenezes@ufpe.br

3 Prof. Instituto Federal de Educação, Ciência e Tecnologia de Roraima, BR 174, Km 512, 69360-971, Caracarai, RR. E-mail: nicolaualves@yahoo.com.br

4 Biológo, doutorando em Tecnologia Energéticas e Nucleares, Dept ${ }^{\mathrm{o}}$ de Energia Nuclear, Av. Prof. Luiz Freire, 1000, Cidade Universitária, 50740-540, Recife, PE. E-mail: darioprimo@gmail.com

5 Eng ${ }^{\mathrm{o}}$ Agr $^{\mathrm{o}}$, Dept $^{\mathrm{o}}$ de Energia Nuclear, Av. Prof. Luiz Freire, 1000, Cidade Universitária, 50740-540, Recife, PE. E-mail: gbru4@ yahoo.com.br

* Autor para correspondência
} 
$\mathrm{N}$ content was greater after surface application of G. sepium prunings. Surface application of manure increased leaf $\mathrm{P}$ concentration, but leaf $\mathrm{K}$ was greater after incorporation of $C$. sonderianus prunings. Maize leaf $\mathrm{N}$ fractions were inversely related to grain productivity.

Key words: Green manure, cattle manure, nitrogen, Zea mays L., Gliricídia sepium

\section{Introdução}

Os solos da região semiárida do Nordeste do Brasil na sua maioria são deficientes em nutrientes, como o nitrogênio e fósforo, decorrente do baixo teor de matéria orgânica (SAMPAIO et al., 1995). O uso de fertilizantes químicos para melhorar a fertilidade do solo não é viável para a grande maioria dos agricultores dessa região devido à irregularidade da ocorrência das chuvas e ao baixo poder aquisitivo desses produtores. Portanto, nesses casos, o manejo da matéria orgânica é a única alternativa para suprir nutrientes às culturas agrícolas (NASCIMENTO et al., 2005). Uma vezque decorrente da disponibilidade de água na época chuvosa, associado a áreas recém desmatadas submetidas a cultivo itinerante favorece a mineralização da matéria orgânica, levando a perdas de produtividade. Esses fatos induzem a reflexão sobre adotar práticas de manejo do solo que priorizem a manutenção da matéria orgânica (MARIN et al., 2006).

Em diversos sistemas de produção à semelhança do semi-árido do Nordeste, a disponibilidade de nitrogênio é quase sempre uns dos fatores limitantes, influenciando o crescimento da planta mais do que qualquer outro nutriente. Ressaltando que a cultura do milho constitui uma cultura de subsistência nessa região (MENEZES et al., 2002), bastante exigente em nitrogênio e potássio, para completar o seu ciclo vegetativo (COELHO; FRANÇA, 1995).

Os adubos orgânicos, principalmente o esterco, são amplamente utilizados nas propriedades agrícolas familiares, como fonte de nutrientes. No entanto, a qualidade e a forma de manejo do esterco podem afetar significativamente o suprimento de nutrientes, principalmente $\mathrm{N}$ às culturas agrícolas (SILVA; MENEZES, 2007). Além disso, cada vez mais se tem difundido o uso de compostos orgânicos e, em menor escala, os adubos verdes, com a utilização de leguminosas e não leguminosas, como fonte de $\mathrm{N}$.

A riqueza de um adubo orgânico em nutrientes depende do material de origem e do processo de produção. Os adubos orgânicos, além de fornecerem nutrientes, destacam-se por um papel muito importante que é o fornecimento de matéria orgânica para melhorar as propriedades físicas, químicas e biológicas do solo, que favorece o equilíbrio da disponibilidade de nutrientes para as plantas (MELÉM JUNIOR et al., 2011).

O adubo orgânico possui um conjunto de propriedades e características diferentes dos adubos minerais. Na maior parte, nitrogênio, enxofre e boro são os nutrientes mais importantes (RAIJ, 1991; STEVENSON, 1994; MOREIRA; SIQUEIRA, 2006).

As variáveis de grande importância fisiológica, tais como acúmulo de $\mathrm{NO}_{3}^{-}$(nitrato), $\mathrm{N}$-amino e açúcares solúveis são fundamentais para a pesquisa em nutrição de plantas e, em especial, da nutrição nitrogenada (MARSCHNER, 1995; COMETTI et al., 2004).

Entretanto, estudos com plantas para avaliar a capacidade de absorção e quantificação das formas orgânicas de $\mathrm{N}$ (N-orgânico) vêm sendo realizados há algum tempo (SOUZA; FERNANDES, 2006) em gramíneas, como capim-colonião (SILVEIRA; SANT'ANNA, 1988), silagem de tifton 85 (PEREIRA et al., 2007) e o arroz (FERNANDES, 1990), em hortaliças como a alface (COMETTI et al., 2004) e com espécies de leguminosas arbóreas (LIMA et al., 2006), mas poucos estudos com o milho e, os existentes são com fertilização 
mineral (BORGES et al., 2006). Não há registro, de estudos de frações nitrogenadas na cultura do milho submetido à adubação orgânica em região semiárida no Brasil.

Diante do exposto, objetivou-se avaliar o efeito do modo de aplicação dos adubos orgânicos sobre as frações nitrogenadas e a sua relação com a produtividade de grãos pelo milho na região semiárida.

\section{Material e Métodos}

O experimento foi desenvolvido na Estação Agroecológica Vila Maria Rita, no município de Taperoá, PB, na microrregião do Cariri, localizado a $07^{\circ} 12^{\prime} 10,8^{\prime \prime} \mathrm{S}$ e $36^{\circ} 49^{\prime} 42,6^{\prime \prime} \mathrm{W}$ com altitude em torno de $520 \mathrm{~m}$. A precipitação pluviométrica média anual da microrregião é $500 \mathrm{~mm}$. Foi observado diariamente e calculado mensalmente a precipitação pluviométrica durante o período em que foi implantado o experimento (Figura 1). O solo da área experimental foi classificado em Neossolo Flúvico. Foram realizadas as análises químicas desse solo $(0,0-0,15 \mathrm{~m})$ e determinados os atributos químicos, antes da aplicação dos tratamentos e semeadura do milho (Zea mays L.). Os valores dessas análises descriminaram $\mathrm{pH}\left(\mathrm{H}_{2} \mathrm{O}\right)=6,74, \mathrm{P}$ $=299,5 \mathrm{mg} \cdot \mathrm{kg}^{-1}$, teor de $\mathrm{K}, \mathrm{Ca}, \mathrm{Mg}, \mathrm{Na}, \mathrm{Al}, \mathrm{Al}+\mathrm{H}$, $\mathrm{SB}, \mathrm{CTC}$ correspondente a 0,$25 ; 3,95 ; 0,62 ; 0,10$; 0,$10 ; 1,32 ; 4,92$ e $6,24 \mathrm{cmol}_{\mathrm{c}} \cdot \mathrm{kg}^{-1} ; \mathrm{V}=78,0 \% ; \mathrm{m}=$ $2,0 \%$; C e $\mathrm{N}$ total $=8,80$ e $0,50 \mathrm{~g}^{\mathrm{kg}} \mathrm{kg}^{-1}$; teor de areia, silte e argila correspondente a 532, 203 e 265 g. $\mathrm{kg}^{-1}$.

Figura 1. Precipitação pluvial mensal no Centro Agroecológico Maria Rita, no município de Taperoá, PB no ano de 2008.

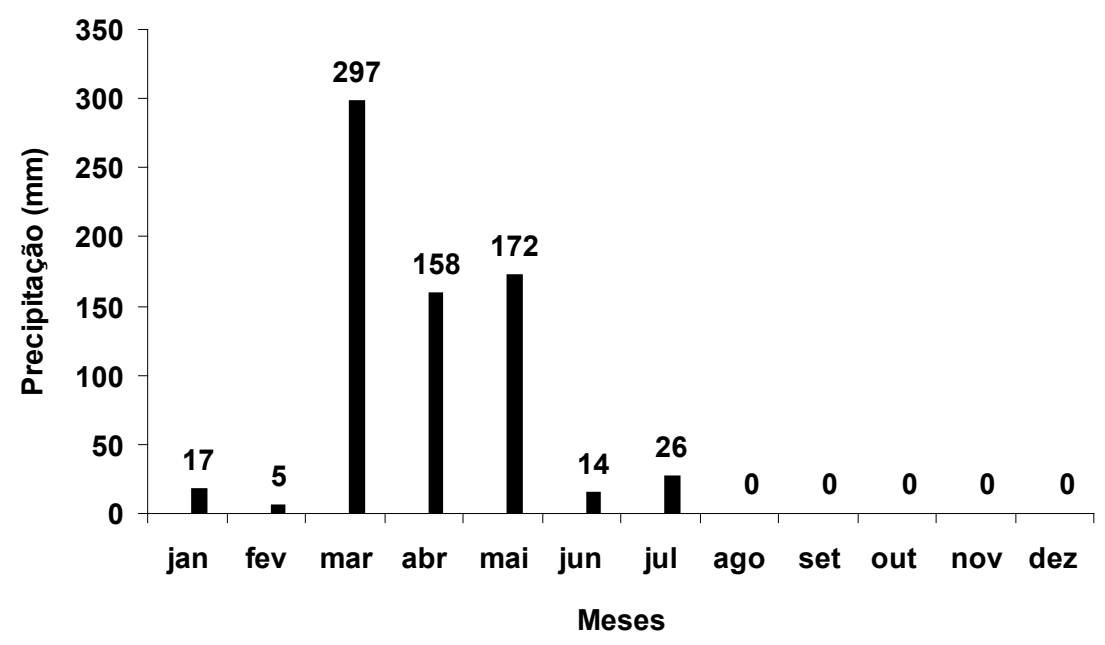

Os materiais orgânicos utilizados consistiram em: marmeleiro (Croton sonderianus), esterco bovino de curral e gliricídia (Gliricídia sepium). O esterco de curral e o marmeleiro foram coletados nas propriedades rurais dessa microrregião, enquanto que a gliricídia foi proveniente de árvores localizadas nas proximidades da área experimental.
As características químicas, determinadas de acordo com Malavolta, Vitti e Oliveira (1997), desses adubos orgânicos utilizados nos tratamentos consistem em: C, N, P, K, Ca, Mg e C/N = 385; 31; 5,$4 ; 21,4 ; 21 ; 0,1$ g. $^{-1}$ e $^{-1}$ 12,4 para a gliricidia; 410 ;

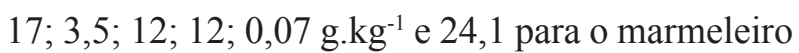

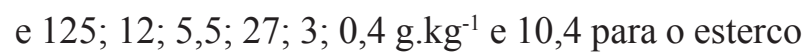
respectivamente. 
O delineamento experimental adotado foi em bloco ao acaso com oito tratamentos e quatro repetições arranjados em um fatorial $(2 \times 3)+2$ que correspondem a dois tipos de manejo de aplicação (incorporado e em superfície), três materiais orgânicos (marmeleiro, gliricídia e esterco) e duas testemunhas, com e sem revolvimento do solo. Os adubos orgânicos e sua forma de aplicação vêm sendo feitos desde o ano de 2007. E no ano de 2008 foi dada continuidade à aplicação desses adubos, momentos antes da semeadura do milho, que consistiram nos seguintes tratamentos: (T1) Controle, sem aplicação dos adubos orgânicos e revolvimento do solo; (T2) Controle, sem aplicação dos adubos orgânicos e com revolvimento do solo; (T3) Aplicação de 15 t.ha $^{-1}$ de biomassa fresca da gliricidia na superfície do solo; (T4) Aplicação e incorporação de 15 t.ha ${ }^{-1}$ de biomassa fresca da gliricidia no solo; (T5) Aplicação de 15 t.ha ${ }^{-1}$ de biomassa fresca do marmeleiro na superfície do solo; (T6) Aplicação e incorporação de 15 t.ha-1 de biomassa do marmeleiro do solo; (T7) Aplicação de 15 t.ha $^{-1}$ de esterco na superfície do solo; (T8) Aplicação e incorporação de 15 t.ha ${ }^{-1}$ de esterco no solo.

O tratamento do solo sem revolvimento e com revolvimento na época da semeadura do milho teve o intuito de verificar o impacto causado à cultura do milho, quando o agricultor faz o revolvimento do solo, durante o preparo deste na época da semeadura do milho na região semi-árida. Nos anos de 20072008 no início das chuvas, geralmente fevereiro a março, os materiais orgânicos foram aplicados em uma dose de 15 t.ha $^{-1}$ de matéria fresca, que corresponde, aproximadamente, a 3,75; 4,90 e 9,70 t.ha ${ }^{-1}$ de matéria seca de gliricídia, marmeleiro e esterco.

Esses adubos orgânicos corresponderam à adição de $\mathrm{N}, \mathrm{P}, \mathrm{K}, \mathrm{Ca}$ e $\mathrm{Mg}$, que consistiram em: 116,$3 ; 20,3 ; 80,3 ; 78,8$ e 0,4 kg.ha-1 ${ }^{-1}$, para a Glirídia; 83,$3 ; 17,2 ; 58,8 ; 59$ e $0,3 \mathrm{~kg} \cdot \mathrm{ha}^{-1}$, para o marmeleiro e 116,$4 ; 53,4 ; 262 ; 29,1$ e $4,0 \mathrm{~kg} \mathrm{ha}^{-1}$, para o esterco. Tanto a gliricídia quanto o marmeleiro tiveram as suas folhas retiradas e os galhos picados, utilizando-se um facão. As folhas e os galhos foram misturados e em seguida aplicados nas parcelas experimentais. Nas parcelas em que o material orgânico foi incorporado, essa prática foi feita manualmente com auxílio de uma enxada de 2,5 libras. As parcelas experimentais foram constituídas das seguintes dimensões, 5 x $4 \mathrm{~m}$, com $6 \mathrm{~m}^{2}$ de área útil, em um total de 150.000 plantas por parcela experimental. O milho da variedade Sergipano foi semeado em quatro fileiras no espaçamento de 1,0 x $0,20 \mathrm{~m}$. Foram semeadas cinco sementes por cova. Nos primeiros 15 dias, após a semeadura, foi feito desbaste de duas plântulas em todas as covas da parcela, deixando apenas três.

O monitoramento fitossanitário, para o controle de pragas, foi feito utilizando produto de origem natural. Foi preparada uma mistura de $2 \mathrm{~kg}$ de folhas verdes de Nin (Azadirachta indica) em 10 litros de água não destilada e após dois dias de repouso fezse pulverização nas folhas das plantas do milho predadas por lagartas.

A amostragem para a diagnose foliar foi coletada no aparecimento da inflorescência feminina. No tecido foliar os teores de $\mathrm{N}, \mathrm{P}, \mathrm{K}, \mathrm{Ca}$ e $\mathrm{Mg}$ foram determinados de acordo com a metodologia descrita por Malavolta, Vitti e Oliveira (1997).

Os teores de nitrogênio total (N-total) nas folhas foram determinados pelo método Microkjeldahl (MALAVOLTA; VITTI; OLIVEIRA, 1997), a destilação e titulação foram realizadas de acordo com Bremmer e Edwards (1965). O teor de $\mathrm{N}$-solúvel foi determinado através da adição de 30 $\mathrm{mL}$ de água destilada em $0,1 \mathrm{~g}$ do tecido foliar seco e moído. Posteriormente, essa mistura foi colocada em "banho-maria" à temperatura de $70^{\circ} \mathrm{C}$ durante 45 minutos. Após esfriar à temperatura ambiente, as amostras foram filtradas, obtendo-se, assim, um extrato com compostos nitrogenados solúveis. Uma alíquota de $10 \mathrm{~mL}$ do extrato filtrado foi colocada em tubo de digestão, juntamente com 1,5 g de $\mathrm{K}_{2} \mathrm{SO}_{4}$, $0,3 \mathrm{~g}$ de $\mathrm{CuSO}_{4}$ e $3 \mathrm{~mL}$ de ácido sulfúrico $\left(\mathrm{H}_{2} \mathrm{SO}_{4}\right)$ 
concentrado. Também foi determinado, no tecido foliar, o teor de nitrato extraído em água a $45^{\circ} \mathrm{C}$ e quantificado colorimetricamente por nitração do ácido salicílico e leitura em espectrofotômetro a 410 nm (CATALDO et al., 1975).

Os teores de $\mathrm{N}$ orgânico solúvel (aminoácidos, aminas, amidas e proteínas solúveis em água) foram obtidos pela diferença entre o teor do $\mathrm{N}$ solúvel e o N-nitrato, enquanto os teores de $\mathrm{N}$-insolúvel (proteínas e ácidos nucléicos) foram calculados pela diferença entre os teores de N-total e os do N-solúvel (GUAZZELLI, 1988; SILVEIRA; SANT'ANNA, 1988). No ano de 2008, no período da colheita, aproximadamente 120 dias após a semeadura das sementes foram quantificados a produção de grãos à $13 \%$ de umidade em cada parcela experimental. Em seguida, sub-amostras dos grãos foram amostrados para determinação no extrato de digestão dos teores de $\mathrm{N}$ total, P e K (MALAVOLTA; VITTI; OLIVEIRA, 1997).

Quinze dias antes da aplicação dos tratamentos e semeadura do milho, o solo da área de cada bloco foi coletado, através de amostragem composta, na profundidade de 0,0 a $0,15 \mathrm{~m}$. Sub-amostras desse solo foi seco ao ar, destorroado e passado em uma peneira $2 \mathrm{~mm}$, constituindo a terra fina seca ao ar (TFSA) e caracterizado quanto aos teores de C orgânico (SNYDER; TROFYMOW, 1984); N total pelo o Kjeldahl (BREMNER; MULVANEY, 1982); Ca e Mg extraídos com KCl 1 mol.L-1 (EMBRAPA, 1997) e dosados por espectrometria de absorção atômica; P, K e Na extraíveis por $\mathrm{Mehlich}^{-1}$, sendo o P determinado por colorimetria e o $\mathrm{K}$ e $\mathrm{Na}$ por fotometria de chama; $\mathrm{pH}$ em água e $\mathrm{KCl} 1 \mathrm{~N}(1: 2,5)$ e granulometria (EMBRAPA, 1997). Amostras dos materiais orgânicos foram analisadas quanto aos teores de N, P e K de acordo com a metodologia descrita por Malavolta, Vitti e Oliveira (1997).

As variáveis analisadas foram produtividades de grãos, teores de $\mathrm{N}, \mathrm{P}, \mathrm{K}, \mathrm{Ca}, \mathrm{Mg}$ e das frações nitrogenadas (nitrato, $\mathrm{N}$ solúvel, $\mathrm{N}$ orgânico solúvel e $\mathrm{N}$ insolúvel) no tecido foliar do milho e teor de
$\mathrm{N}$, P e K nos grãos. Os dados foram submetidos à análise de variância, e as médias desses dados comparadas pelo teste de Scott-Knott a 5\% de significância, utilizando-se o programa estatístico SISVAR (FERREIRA, 2003).

\section{Resultados e Discussão}

\section{Produção e teor de nutrientes dos grãos}

Observou-se que as produtividades de grãos do milho variaram de 1380 a $3141 \mathrm{~kg} \cdot \mathrm{ha}^{-1}$, quando se aplicou o adubo em superfície e de 2353 a 2797 kg.ha- ${ }^{-1}$, quando aplicado e incorporado ao solo (Tabela 1). O incremento entre a maior e a menor produtividade de grãos foi de $127 \%$, quando aplicado em superfície e de 19\%, quando aplicado e incorporado ao solo. Possivelmente, o uso agrícola com intensivo revolvimento do solo, como no tratamento controle altera o conteúdo de matéria orgânica, com aumento imediato da disponibilidade de N, P e S (BAYER; MIELNICZUK, 2008).

Avaliando a produtividade do milho submetido à aplicação de 20 t.ha ${ }^{-1}$ de biomassa de gliricidia e o esterco incorporado ao solo, Marin, Menezes e Salcedo (2007) obtiveram em três cultivos consecutivos, produtividades de grãos menores que as do presente estudo. No modo de aplicação em superfície, a maior produtividade de grãos foi obtida em valores absolutos, quando se aplicou e incorporou ao solo a biomassa do marmeleiro (3141 kg.ha-1), que diferiu significativamente do tratamento controle, que obteve produtividade de grãos em torno de $1380 \mathrm{~kg} \cdot \mathrm{ha}^{-1}$. Essa superioridade na produtividade de grãos entre os tratamentos marmeleiro e controle correspondeu a $127 \%$. Fato que comprova a eficiência da aplicação da biomassa do marmeleiro, como adubo verde nessa região. Essas produções de grãos foram superiores a produtividade média regional para a cultura do milho que é de $800 \mathrm{~kg}$.ha- ${ }^{-1}$ de grãos (MENEZES; SAMPAIO, 2000). Por outro lado, quando se avaliou os modos de aplicação dos adubos, verifica-se que no tratamento controle, com revolvimento do solo ocorreu superioridade 
em relação ao modo de aplicação em superfície, em que não houve revolvimento do solo (Tabela 1). Possivelmente, o uso agrícola com intensivo revolvimento do solo, como em um dos tratamentos controle altera o conteúdo de matéria orgânica, através da mineralização, favorecendo o aumento imediato da disponibilidade de N, P e S (BAYER; MIELNICZUK, 2008). Enquanto, quando se utilizou o esterco, a incorporação ao solo, favoreceu uma menor produtividade de grãos (Tabela 1), provavelmente, decorrente da maior atividade microbiana, que favoreceu a mineralização desse adubo e, uma possível baixa disponibilidade de nutrientes sincronizada com a demanda nutricional do milho.

O teor de $\mathrm{N}$ nos grãos no modo de aplicação em superfície foi superior para o esterco, a glirícidia e o marmeleiro em relação ao tratamento controle. Quando se avaliou os modos de aplicação dos adubos, verificou-se efeito significativo apenas no tratamento controle, com revolvimento do solo, favorecendo o maior teor de $\mathrm{N}$ nos grãos de milho. Para o teor de P nos grãos, apenas verificou efeito do modo de aplicação, para o esterco, onde o modo em superfície foi superior ao modo incorporado, com aumento correspondendo a $10 \%$, enquanto para o teor de K não ocorreu efeito entre adubos e modos de aplicação (Tabela 1). Curi, Kampf e Marques. (2005) relatam que em solos poucos intemperizados a liberação de K pelos feldspatos é capaz de suprir a demanda das plantas, por alguns ciclos. Fato que, possivelmente, esteja ocorrendo no Neossolo Flúvico da região do Cariri paraibano, onde foi desenvolvido esse estudo.

Tabela 1. Produtividade (Prod), teor de N (tNgr), de P (tPgr) e K (tKgr) nos grãos do milho após diferentes modos de aplicação dos adubos orgânicos em um Neossolo Flúvico. Taperoá-PB 2008.

\begin{tabular}{lcccccccc}
\hline Tratamentos & \multicolumn{2}{c}{ Prod } & \multicolumn{2}{c}{ TNgr } & \multicolumn{2}{c}{ tPgr } & \multicolumn{2}{c}{ tKgr } \\
\hline & $-{ }^{(1)} \mathbf{S}$ & ${ }^{(2)} \mathbf{I}$ & $\mathbf{S}$ & $\mathbf{I}$ & $\mathbf{S}$ & $\mathbf{I}$ & $\mathbf{S}$ & I \\
Controle & $1380 \mathrm{bB}^{(3)}$ & $2797 \mathrm{aA}$ & $15,00 \mathrm{bB}$ & $19,75 \mathrm{aA}$ & $7,38 \mathrm{aA}$ & $7,46 \mathrm{aA}$ & $8,39 \mathrm{aA}$ & $8,04 \mathrm{aA}$ \\
Gliricidia & $2733 \mathrm{aA}$ & $2734 \mathrm{aA}$ & $19,00 \mathrm{aA}$ & $19,00 \mathrm{aA}$ & $7,07 \mathrm{aA}$ & $7,26 \mathrm{aA}$ & $7,89 \mathrm{aA}$ & $8,27 \mathrm{aA}$ \\
Esterco & $3138 \mathrm{aA}$ & $2353 \mathrm{aB}$ & $19,50 \mathrm{aA}$ & $19,75 \mathrm{aA}$ & $7,64 \mathrm{aA}$ & $6,97 \mathrm{aB}$ & $8,70 \mathrm{aA}$ & $8,27 \mathrm{aA}$ \\
Marmeleiro & $3141 \mathrm{aA}$ & $2659 \mathrm{aA}$ & $18,25 \mathrm{aA}$ & $19,00 \mathrm{aA}$ & $7,59 \mathrm{aA}$ & $7,75 \mathrm{aA}$ & $8,19 \mathrm{aA}$ & $8,24 \mathrm{aA}$ \\
\hline
\end{tabular}

${ }^{(1)}$ S - sem incorporação dos adubos orgânicos no Neossolo Flúvico antes da semeadura do milho; ${ }^{(2)}$ I - com incorporação dos adubos orgânicos no Neossolo Flúvico antes da semeadura do milho. ${ }^{(3)}$ Médias seguidas pela mesma letra maiúscula nas linhas, dentro de cada variável avaliada e minúscula nas colunas dentro de cada modo de aplicação dos adubos orgânicos não diferem estatisticamente entre si pelo teste Scott e-Knott (1974) ao nível de 5\% de probabilidade.

Teor das frações nitrogenadas e de nutrientes no tecido foliar

Os teores de $\mathrm{N}$ na folha do milho foi considerado adequado (27,5 - 32,5 mg. $\left.\mathrm{g}^{-1}\right)$ de acordo com Malavolta, Vitti e Oliveira (1997), apenas para o tratamento esterco, gliricidia e marmeleiro, quando aplicados em superfície e no tratamento controle, no modo de aplicação incorporado (com revolvimento de solo) (Tabela 2).
Apesar de o nitrato ser a menor fração nitrogenada determinada no tecido foliar, como já verificado em outros estudos (COMETTI et al., 2004; BORGES et al., 2006), observou-se que apenas o modo de aplicação incorporado dos adubos orgânicos mostrou efeito significativo entre os tipos de adubos orgânicos avaliados, sendo que o tratamento controle foi significativamente superior aos demais tratamentos. O uso agrícola do solo com intensivo revolvimento, como em um dos 
tratamentos controle altera o conteúdo de matéria orgânica, através da mineralização, favorecendo $\mathrm{o}$ aumento imediato da disponibilidade de N, P e S (BAYER; MIELNICZUK, 2008). Quando se avaliou o modo de aplicação, em superfície ou incorporado notou-se que a aplicação da gliricidia e do esterco em superfície foi superior ao modo incorporado, quanto ao teor de nitrato nas folhas.

Com relação aos teores de $\mathrm{N}$ solúvel nas folhas, no modo de aplicação em superfície, os tratamentos controle e gliricidia foram superiores em relação ao esterco e ao marmeleiro; enquanto, no modo incorporado, o tratamento controle, ou seja, com revolvimento do solo, foi superior aos demais tratamentos estudados (Tabela 2), possivelmente decorrentes da maior concentração de nitrato no tecido foliar no tratamento com revolvimento, que proporcionou maiores teores de compostos nitrogenados solúveis. Entre os modos de aplicação dos adubos, apenas o esterco não apresentou efeito entre os modos de aplicação, para o teor de $\mathrm{N}$ solúvel (Tabela 2).

As frações nitrogenadas, $\mathrm{N}$ orgânico solúvel e $\mathrm{N}$ insolúvel não apresentaram efeitos significativos entre os materiais orgânicos aplicados e os modos de aplicação destes. A fração de $\mathrm{N}$ orgânico foliar no modo em superfície apresentou os menores teores para os tratamentos esterco e marmeleiro em superfície e incorporado ao solo (Tabela 3), os quais apresentaram as maiores produtividades de grãos (Tabela 2). Esse comportamento, de acordo com Imsande e Touraine (1994) é devido que na fase reprodutiva, a planta diminui a taxa de redução de nitrato em função da remobilização do $\mathrm{N}$ foliar para o desenvolvimento das inflorescências, aumentando a exportação de aminoácidos das folhas.

Essa remobilização provavelmente explica o comportamento fisiológico das plantas de milho, que apresentaram a menor produtividade de grãos (Tabela 2) e um dos maiores teores de $\mathrm{N}$ solúvel (Tabela 2). Comportamento conhecido como efeito concentração, já que estruturalmente, as plantas desenvolveram-se pouco, favorecendo uma maior concentração dessa fração de $\mathrm{N}$ no tecido foliar. Confirmando que, a fração $\mathrm{N}$ insolúvel foi considerada a maior fração no tecido foliar do milho (Tabela 2).

Tabela 2. Teores de $\mathrm{N}$ total, nitrato, $\mathrm{N}$ solúvel, $\mathrm{N}$ orgânico solúvel e $\mathrm{N}$ insolúvel no tecido foliar do milho, após aplicação dos adubos orgânicos em um Neossolo Flúvico.

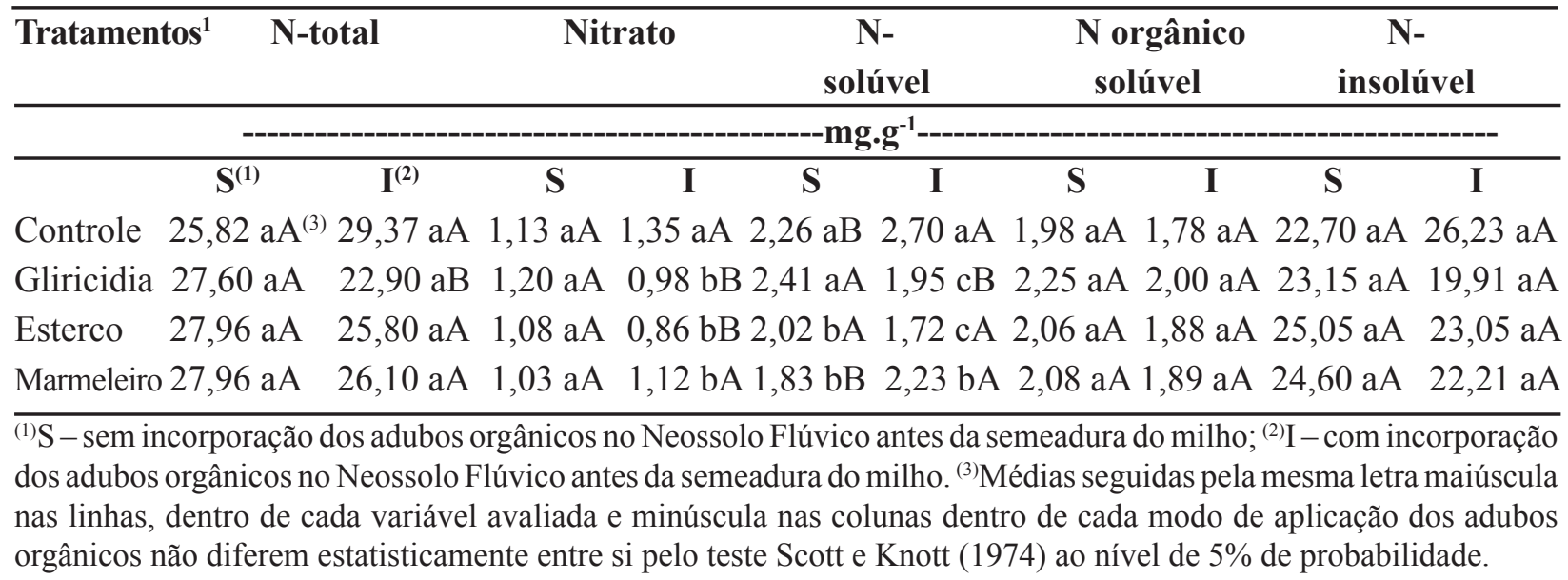


Os teores dos nutrientes no tecido foliar do milho foram influenciados pelo tipo e modo de aplicação dos adubos orgânicos, exceto os de N, P e K para os tratamentos aplicados, quando se utilizou o modo de aplicação em superfície (Tabela 3). No geral, os teores no tecido foliar de $\mathrm{P}, \mathrm{K}$ e Ca estão dentro da faixa considerada pela literatura (MALAVOLTA; VITTI; OLIVEIRA, 1997) como adequado (P: 2,53,5; K: 17,5-22,5; Ca: 2,5-4,0 mg.g $\mathrm{g}^{-1}$ ), para o adequado desenvolvimento das plantas, enquanto os teores de $\mathrm{Mg}$ foram considerados abaixo do adequado (2,5-4,0 $\mathrm{mg} . \mathrm{g}^{-1}$ ), para o ótimo desenvolvimento das plantas de milho.

Para os teores de $\mathrm{P}$ e $\mathrm{K}$, apenas o modo de aplicação dos adubos incorporados apresentou efeito significativo entre os materiais orgânicos aplicados, com superioridade dos tratamentos controle e gliricidia sobre os demais. Possivelmente, favorecido pelo alto teor de P nesse Neossolo Flúvico, que é decorrente do seu material de origem. Enquanto que, para o teor de K verificou superioridade do marmeleiro sobre os demais tratamentos avaliados (Tabela 3 ).

$\mathrm{O}$ teor de $\mathrm{Ca}$ no tecido foliar, para o modo de aplicação em superfície mostrou que a gliricida foi superior ao controle, esterco e marmeleiro. Apesar dos teores de $\mathrm{Ca}$ e $\mathrm{Mg}$ no Neossolo Flúvico serem considerados altos, de acordo com a Empresa de
Assistência Técnica e Extensão Rural (1979), mas as leguminosas, como a gliricidia necessitam de cálcio para a formação dos nódulos no sistema radicular, para a fixação biológica de nitrogênio atmosférico (MARSCHNER, 1995; EPSTEIN; BLOOM, 2006). No modo de aplicação incorporado, verificou-se que a gliricidia, o esterco e o marmeleiro foram superiores ao controle, possivelmente, devido ao maior aporte desse nutriente ao solo. Quando se compara o modo de aplicação verifica-se que no controle (sem revolvimento do solo) proporcionou maior teor de $\mathrm{Ca}$ nas folhas, divergindo do tratamento marmeleiro, que foi verificado maiores teores desse nutriente nas folhas, quando incorporado o material vegetal ao solo. Os teores de $\mathrm{Mg}$ no tecido foliar do milho no modo de aplicação em superfície foram superiores para o tratamento gliricidia e no modo de aplicação incorporado, no gliricidia e marmeleiro, apesar de não serem suficientes para suprir a demanda das plantas de milho (Tabela 3). Essa baixa absorção de Mg pelo milho, possivelmente, foi decorrente da alta competição com o cálcio e o potássio do solo no momento de absorção pelas raízes, uma vez que, de acordo com Coelho e França (1995), o potássio é um dos nutrientes mais exigido em demanda nutricional por esta cultura. No teor de Mg no tecido foliar, apenas o marmeleiro quando incorporado demonstrou superioridade em relação a quando aplicado em superfície (Tabela 3).

Tabela 3. Teores de fósforo $(\mathrm{P})$, potássio $(\mathrm{K})$, cálcio $(\mathrm{Ca})$ e magnésio $(\mathrm{Mg})$ no tecido foliar do milho após aplicação dos adubos orgânicos em um Neossolo Flúvico.

\begin{tabular}{|c|c|c|c|c|c|c|c|c|}
\hline \multirow{3}{*}{ Tratamentos $^{1}$} & \multicolumn{2}{|c|}{$\mathbf{P}$} & \multicolumn{2}{|c|}{$\mathbf{K}$} & \multicolumn{2}{|c|}{$\mathbf{C a}$} & \multicolumn{2}{|c|}{ Mg } \\
\hline & \multicolumn{8}{|c|}{ 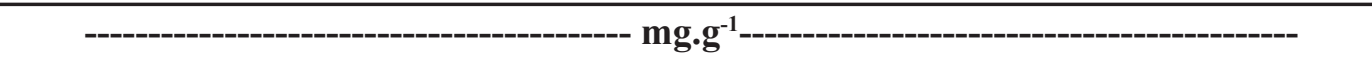 } \\
\hline & $\mathbf{S}^{(\mathbf{1})}$ & $\mathbf{I}^{(2)}$ & $\mathbf{S}$ & I & $\mathbf{S}$ & I & $\mathbf{S}$ & I \\
\hline Controle & $3,69 \mathrm{aA}^{(3)}$ & $3,93 \mathrm{aA}$ & 23,18 aA & $21,41 \mathrm{bA}$ & $9,97 \mathrm{bA}$ & $8,10 \mathrm{bB}$ & $1,56 \mathrm{bA}$ & $1,66 \mathrm{bA}$ \\
\hline Gliricidia & 3,71 aA & $4,61 \mathrm{aA}$ & $23,74 \mathrm{aA}$ & $22,54 \mathrm{bA}$ & $12,24 \mathrm{aA}$ & $10,99 \mathrm{aA}$ & $2,27 \mathrm{aA}$ & $2,10 \mathrm{aA}$ \\
\hline Esterco & $4,19 \mathrm{aA}$ & $3,06 \mathrm{bB}$ & $21,24 \mathrm{aA}$ & $20,68 \mathrm{bA}$ & $9,40 \mathrm{bA}$ & $9,91 \mathrm{aA}$ & $1,53 \mathrm{bA}$ & $1,32 \mathrm{bA}$ \\
\hline Marmeleiro & $3,06 \mathrm{aA}$ & $3,42 \mathrm{bA}$ & $23,22 \mathrm{aA}$ & $25,17 \mathrm{aA}$ & $7,33 \mathrm{cB}$ & $10,64 \mathrm{aA}$ & $1,42 \mathrm{bB}$ & $2,12 \mathrm{aA}$ \\
\hline
\end{tabular}




\section{Conclusões}

A aplicação e incorporação da biomassa do marmeleiro, o esterco bovino de curral e a biomassa da gliricidia no solo sem revolvimento influenciaram positivamente na produtividade de grãos de milho.

$\mathrm{O}$ esterco quando aplicado em superfície favoreceu incremento na produtividade de grãos, quando comparado ao modo incorporado.

Os adubos orgânicos e os modos de aplicação ao solo tiveram influências diferenciadas nos teores de nutrientes nas folhas do milho.

As frações nitrogenadas no tecido foliar não acompanhou a tendência da produtividade de grãos, ou seja, os tratamentos que proporcionaram as maiores produtividades de grãos apresentaram as menores frações nitrogenadas, por outro lado, quando a produtividade de grãos foi menor, maiores foram às frações de $\mathrm{N}$ no tecido foliar.

\section{Agradecimentos}

À Fundação de Amparo à Ciência e Tecnologia do Estado de Pernambuco (FACEPE) processo APQ-011-5.01/08 pelo apoio financeiro, com vistas à realização do presente estudo.

\section{Referências}

BAYER, C.; MIELNICZUK, J. Dinâmica e função da matéria orgânica. In: SANTOS, G. A.; SILVA, L. S.; CANEllas, L. P.; CAMARGO, F. A. O. (Ed.). Fundamentos da matéria orgânica do solo: ecossistemas tropicais e subtropicais. 2. ed. Porto Alegre: Metrópole, 2008. p. 7-18.

BORGES, E. A.; FERNANDES, M. S.; LOSS, A.; SILVA, E. E.; SOUZA, S. R. Acúmulo e remobilização de nitrogênio em variedades de milho. Caatinga, Mossoró, v. 19, n. 3, p. 278-286, jul./set. 2006.

BREMMER, J. M.; EDWARDS, A. P. Determination and isotope ratio analysis of different forms of nitrogen in soils: I. Apparatus and procedures for distillation and determination for ammonium. Soil Science Society of American Proceedings, Madison, v. 29, n. 5, p. 504-507, sept./oct. 1965.
BREMNER, J. M.; MULVANEY, C. S. Nitrogen-total. In: PAGE, A. L.; MILLER, R. H.; KEENEY, D. R. (Ed.). Methods of soil analysis. Chemical and microbiological properties. Madison, ASA-SSSA, 1982. Part. 2. p. 595624. (Agronomy Monograph, 9).

CATALDO, D. A.; HAAROON, M.; SCHRADER, L. E.; YOUNGS, V. L. Rapid colorimetric determination of nitrate in plant tissue of nitration of salicylic acid. Communications in Soil Science and Plant Analysis, New York, v. 6, p. 71-90, 1975.

COELHO, A. M.; FRANÇA, G. E. Seja doutor do seu milho: nutrição e adubação. 2. ed. Piracicaba: Potafos, 1995. 9 p. (Arquivo do Agrônomo, 2).

COMETTI, N. N.; MATIAS, G. C.; ZONTA, E.; MARY, W.; FERNANDES, M. S. Compostos nitrogenados e açucares solúveis em tecidos de alface orgânica, hidropônica e convencional. Horticultura Brasileira, Brasília, v. 22, n. 4, p. 748-753, 2004.

CURI, N.; KAMPF, N.; MARQUES, J. J. Mineralogia e formas de potássio em solos brasileiros. In: YAMADA, T.; ROBERTS, T. L. (Ed.). Potássio na agricultura brasileira. Piracicaba: Potafos, 2005. p. 71-91.

EMPRESA DE ASSISTÊNCIA TÉCNICA E EXTENSÃO RURAL - EMATER. Manual de sugestão de adubação para o estado da Paraíba. Primeira aproximação. João Pessoa: EMATER, 1979. 105 p.

EMPRESA BRASILEIRA DE PESQUISA AGROPECUÁRIA - EMBRAPA. Serviço Nacional de Levantamento e Conservação de Solos. Manual de métodos de análise de solos. 2. ed. Rio de Janeiro: EMBRAPA, Centro Nacional de Pesquisa de Solos, 1997. $212 \mathrm{p}$.

EPSTEIN, E.; BLOOM, A. Nutrição mineral: princípios e perspectivas. 2. ed. Londrina: Editora Planta. 2006. 403 p.

FERNANDES, M. S. Efeitos de fontes e níveis de nitrogênio sobre a absorção e assimilação de $\mathrm{N}$ em arroz. Revista Brasileira de Fisiologia Vegetal, Londrina, v. 2, n. 1, p. 1-6, 1990.

FERREIRA, D. S. SISVAR: versão 4. 6. Lavras: DEX/ UFLA, 2003. Software.

GUAZZELLI, E. M. F. M. Efeito de nitrato e amônio no crescimento, assimilação e eficiência de utilização do nitrogênio por cultivares de feijoeiro (Phaseolus vulgaris L.) na fase inicial de crescimento. 1988. Dissertação (Mestrado em Solos e Nutrição de Plantas) - Escola Superior de Agricultura de Lavras, Lavras, MG.

IMSANDE, J.; TOURAINE, B. N. Demand and regulation of nitrate uptake. Plant Physiology, Lancaster, 
v. 105, n. 1, p. 3-7, 1994.

LIMA, A. L. S.; ZANELLA, F.; SCHIAVINATO, M. A.; HADDAD, C. R. B. Nitrogenous compounds, phenolic compounds and morphological aspects of leaves: comparison of deciduous and semideciduous arboreal legumes. Scientia Agrícola, Piracicaba, v. 63, n. 1, p. 4045, 2006.

MALAVOLTA, E.; VITTI, G. C.; OLIVEIRA, S. A. de. Avaliação do estado nutricional das plantas: princípios e aplicações. 2. ed. Piracicaba: POTAFOS, 1997. 319 p.

MARIN, A. M. P.; MENEZES, R. S. C.; SALCEDO, I. H. Productivity of maize intercropped or not with gliricidia ammended with two organic fertilizers. Pesquisa Agropecuária Brasileira, Brasília, v. 42, n. 5, p. 669-677, 2007.

MARIN, A. M. P.; MENEZES, R. S. C.; SILVA, E. D.; SAMPAIO, E. V. S. B. Efeito da Gliricidia sepium sobre nutrientes do solo, microclima e produtividade do milho em sistema agroflorestal no Agreste paraibano. Revista Brasileira de Ciência do Solo, Viçosa, v. 30, n. 3, p. 555564, 2006.

MARSCHNER, H. Mineral nutrition in higher plants. London: Academic, 1995. 889 p.

MELÉM JÚNIOR, N. J.; BRITO, O. R.; FONSECA JÚNIOR, N. S.; FONSECA, I. C. B.; AGUIAR, S. $X$. Nutrição mineral e produção de feijão em áreas manejadas com e sem queima de resíduos orgânicos e diferentes tipos de adubação. Semina: Ciências Agrárias, Londrina, v. 32, n. 1, p. 7-18, 2011.

MENEZES, R. S. C.; SAMPAIO, E. V. S. B. Agricultura sustentável no semi-árido nordestino. In: OLIVEIRA, T. S.; ROMERO, R. E.; ASSIS JUNIOR, R. N.; SILVA, J. R. C. S. (Org.). Agricultura, sustentabilidade e o semiárido. Fortaleza: SBCS, DCS-UFC, 2000, p. 20-46.

MENEZES, R. S. C.; SAMPAIO, E. V. S. B.; SILVEIRA, L. M.; TIESSEN, H.; SALCEDO, I. H. Produção de batatinha com incorporação de esterco e/ou crotalária no Agreste paraibano. In: SILVEIRA, L.; PETERSEN, P.; SABOURIN, E. (Org.). Agricultura familiar $e$ agroecologia no semi-árido: avanços a partir do agreste da Paraíba. Rio de Janeiro: AS-PTA, 2002. p. 261-270.

MENEZES, R. S. C.; SILVA, T. O. Mudanças na fertilidade de um Neossolo Regolítico após seis anos de adubação orgânica. Revista Brasileira de Engenharia Agrícola e Ambiental, Campina Grande, v. 12, n. 3, p. 251-257. 2008.

MOREIRA, F. M. S.; SIQUEIRA, J. O. Microbiologia e bioquímica do solo. 2. ed. Lavras: UFLA, 2006. 729 p.

NASCIMENTO, J. T.; SILVA, I. F.; SANTIAGO, R. D.;
SILVA NETO, L. F. Efeito de leguminosas nos atributos físicos e carbono orgânico de um Luvissolo. Revista Brasileira de Ciência do Solo, Viçosa, v. 29, n. 5, p. 825$831,2005$.

PEREIRA, E. S.; ARRUDA, A. M. V.; MIZUBUTI, I. Y.; CAVALCANTE, M. A. B.; RIBEIRO, E. L. A.; OLIVEIRA, S. M. P.; RAMOS, B. M. O.; COSTA, J. B. Frações nitrogenadas e de carboidratos e cinética ruminal da matéria seca efibra em detergente neutro de silagens de tifton 85 (Cynodon spp.). Semina: Ciências Agrárias, Londrina, v. 28, n. 3, p. 521-528, 2007.

RAIJ, B. V. Fertilidade do solo e adubação. Piracicaba: Editora Agronômica Ceres, 1991. 343 p.

SAMPAIO, E. V. S. B.; SALCEDO, I. H.; SILVA, V. M.; ALVES, G. D. Capacidade de suprimento de $\mathrm{N}$ e resposta à fertilização de 20 solos de Pernambuco. Revista Brasileira de Ciência do Solo, Campinas, v. 20, n. 1, p. 269-279, 1995.

SCOTT, A. J.; KNOTT, M. A cluster analysis method for grouping means in the analysis of variance. Biometrics, Washington, v. 30, n. 3, p. 507-512, sept. 1974.

SILVA, T. O.; MENEZES, R. S. C. Adubação orgânica da batata com esterco e, ou, Crotalaria juncea. II. Disponibilidade de N, P e K no solo ao longo do ciclo de cultivo. Revista Brasileira de Ciência do Solo, Viçosa, v. 31, n. 1, p. 51-61, 2007.

SILVEIRA, J. S. M.; SANT'ANNA, R. Efeitos de nitrato e do amônio no crescimento e fracionamento do $\mathrm{N}$ em capim-colonião. Pesquisa Agropecuária Brasileira, Brasília, v. 23, n. 2, p. 135-143, fev. 1988.

SNYDER, J. D.; TROFYMOW, J. A. A rapid accurate wet oxidation diffusion procedure for determining organic and inorganic carbon in plant and soil samples. Communications in Soil Science Plant Analysis, New York, v. 15, n. 5, p. 587-597, 1984.

SOUZA, S. R.; FERNANDES, M. S. Nitrogênio. In: FERNANDES, M. S. (Ed.). Nutrição mineral de plantas. Viçosa, MG: SBCS, 2006, p. 215-252.

STEVENSON, F. J. Humus chemistry: genesis, composition, reactions. 2. ed. New York: Willey, 1994. $496 \mathrm{p}$. 